successful in this than in providing a geographically comprehensive coverage of the literature to amphibian research the references to the work of continental Europeans, particularly the Italians, are very sparse.

Perhaps the most valuable part of the book is that dealing with evolution and taxonomy. Since Noble's day, many new species have been described and the classification of amphibians has undergone radical changes. Duellman and Trueb draw on data from a variety of sources, including cytogenetics, molecular biology and biogeography, to present a coherent and up-to-date account of amphibian phylogeny.

The text is clear and concise and richly illustrated with diagrams and numerous photographs, though some of these are too indistinct to be very informative. Amphibians and their fascinating and varied habits have long deserved a major textbook. This book goes some way towards being all one could wish for and is likely to be an important source of reference for several years.

Tim Halliday is a Reader in the Department of Biology, Open University, Walton Hall, Milton Keynes MK7 6AA, UK.

\section{A sense of the past}

\section{Patrick Rabbitt}

Neuropsychology of Memory. Edited by Larry R. Squire and Nelson Butters. Guilford Press: 1985. Pp.655. \$75, £62.50.

AT FIRST sight this is yet another bulky, and startlingly expensive, compendium of articles. It consists of 54 review and experimental papers, loosely organized under three headings: "Studies of Normal and Abnormal Memory in Humans", "Studies of Memory in Non-Human Primates" and "Studies of Memory in Nonprimates: Physiology, Pharmacology and Behaviour". On closer reading one finds that it is brilliantly edited. The contributors have not merely been selected for eminence, but because they have something important to say - and they have been disciplined to say it very concisely. In total, however, the book reads like a collection of reports by members of an irreconciliable committee, but this perhaps is the most honest and useful reflection of our current knowledge of the nature and pathology of memory.

Mayes and Meudell capture some of the main tensions in their insightful and critical review. Experts disagree whether "amnesia" is a unitary, or a multiple condition; as to which precise locus of damage to a human or animal brain produces the condition; and as to precisely what disabilities distinguish the "amnesic syndrome" from non-pathological "poor memory" and whether this syndrome is produced by damage to a single critical area or varies with idiosyncratic patterns of multiple lesions. But possibly the most important contribution of this book is that it forces us to recognize an even more fundamental weakness in memory studies: the functional descriptive framework in which all theories have been cast, all experiments designed and all results interpreted over the past 30 years is becoming increasingly unsatisfactory, but no useful alternative has yet been worked out.

This tacit framework has been that "in- formation" from sense organs is "filtered" by a process known as "selective attention". It is then (or later) "encoded" and then (or later) "stored" as an "engram" which is later "retrieved" when required. Studies of memory have attempted to reveal the characteristics of each of these three hypothetical "information processing stages". A tape recorder can be an apt metaphor for this framework as Rose points out in his review, but he goes on further to describe its weakness.

A good example of this weakness is to be found in the paper by Hall and Loftus who consider the case where people experience a particular event and then, subsequently, receive further information which bears upon it and which, apparently, makes them misreport the original details in good faith. The "tape and tape recorder" metaphor rigidly restricts alternative explanations to "overwriting", but the main trouble with this simple underlying model is that it is hard to disprove in specific cases. Even results discrepant from Loftus's, such as those of Bowers and Bekerian, can be re-cast in the same context.

To escape the pervasive assumptions of this framework we must consider how inadequate they are to interpret the more subtle phenomena of memory loss. For example Cermak, greatly extending observations by Kinsbourne, points out that early "memories" produced by amnesics have the characteristic of inferential reconstructions. When pressed, a patient may admit that he cannot recollect any specific episode in his life when he went sailing, but can nevertheless well recall the nature of the sport and, from other incidental evidence, can specify a period of his life when he frequently sailed. Thus the interesting thing about memory is that "retrieval" of information is not simple "reading" of passive "records" by a "tape head", but rather a process of inferential reconstruction - at least as complex as that which occurs in the perceptual interpretation of sensory events. Why has the Lockian associationist fallacy, so long dismissed from perception, persistently lingered in memory studies?
It has been inevitable that rival theories of amnesia should also have been proposed in terms of loci of deficit within this three-stage model. Since it is logically impossible to demonstrate that a given piece of information is not held, albeit incommunicado, in "memory store", the trichotomy becomes a dichotomy - disturbances of encoding of relevant information (e.g. Butters and Cermak) or disturbances of "automatic" encoding (e.g. Hirst) as against disturbances of retrieval processes (e.g. Weiskrantz and Warrington). Once again, the model carries restrictive conviction, and even encourages very useful applied work - such as Mathis and Korner's demonstration, in this book, that, like normal people, amnesic patients are helped to learn word lists by a variety of mnemonic techniques.

Thus, though the book will be very helpful to all trying to find their bearings in a complex literature, perhaps its main contribution is to force on us the embarrassment of recognizing that we know that the models of memory we still use are inadequate, but that we do not know how to do better. Perhaps one way out of this is to try and define clearly what kind of model we now need. Perhaps, to shake us loose from our restrictive assumptions, we need a few Zen koans to meditate? In his excellent initial chapter, Craik, who gets nearer to the heart of these issues than any commentators before him, seems to attempt just this useful provocation:

if memory is like perceiving, then it is perhaps no more likely that memory traces exist in the absence of remembering than it is that percepts exist in the absence of perceiving

and

Good memory for an event is associated with situations in which the event is related to the subject's past knowledge in a meaningful way, yet is also treated in a way that is distinctive from this past knowledge

and

students of memory should not be striving to model the system "at rest" or in isolation - that is, as some entity with an existence separate from its activities. Rather our goal should be to model the interactions themselves - the interactions among tasks, environmental events, and mental representations of past knowledge. Sensai!

Patrick Rabbitt is Director of the Age and Cognitive Performance Research Centre, University of Manchester, Manchester M13 9PL, UK.

\section{New in paperback}

- The Great Mental Calculators: The Psychology, Methods, and Lives of Calculating Prodigies, Past and Present by Steven B. Smith. Publisher is Columbia University Press, price is \$15. For review see Nature 310, 79 (1984).

- Glimpsing an Invisible Universe: The Emergence of X-ray Astronomy by Richard F. Hirsh. Publisher is Cambridge University Press, price is $£ 8.95, \$ 17.95$. For review see Nature 306, $508(1983)$ 